Review Article

\title{
Point of care ultrasound for rapid assessment and treatment of palliative care patients in acute medical settings
}

\author{
Neal Breakey ${ }^{\mathrm{a}, \mathrm{b}, *}$, Joseph Osterwalder ${ }^{\mathrm{c}}$, Gebhard Mathis ${ }^{\mathrm{d}}$, Beat Lehmann ${ }^{\mathrm{b}}$, Thomas C Sauter ${ }^{\mathrm{b}, \mathrm{e}}$ \\ ${ }^{a}$ Department of Medicine, Spital Emmental, Burgdorf, Switzerland \\ ${ }^{\mathrm{b}}$ Department of Emergency Medicine, Inselspital, Bern University Hospital, University of Bern, Bern, Switzerland \\ ${ }^{\mathrm{c}}$ Permanence Polipraxis, St. Gallen, Switzerland \\ ${ }^{\mathrm{d}}$ Praxis für Innere Medizin, Rankweil, Austria \\ ${ }^{\mathrm{e}}$ Medical Skills Lab, Charité Medical School Berlin, Berlin, Germany
}

A R T I C L E I N F O

\section{Keywords:}

POCUS

Ultrasound

Palliative care

Internal medicine

Acute medicine

\begin{abstract}
A B S T R A C T
The combination of an ageing population with improving survival in malignant and non-malignant disease processes results in a growing cohort of patients with advanced or end-stage chronic diseases who require acute medical care. Emergency care has historically been stereotyped as the identification and treatment of acute lifethreatening problems. Although palliative care may be considered to be new to the formal curriculum of emergency medicine, in many domains the ultrasound skillset of a physician in acute medical care can be efficaciously deployed the benefit of patients with both malignant and non-malignant disease processes that require palliative care in the full breadth of acute healthcare settings.

In diagnostic domains (abdominal pain, urinary tract obstruction, dyspnoea, venous thromboembolism and musculoskeletal pain) and for specific intervention guidance (thoracentesis, paracentesis, venous access, regional anaesthesia and musculoskeletal interventions) we suggest that POCUS has the potential to streamline improve patient satisfaction, streamline diagnostic strategies, optimise patient length of stay, expedite timely symptomatic relief and reduce complications in this important patient population.

POCUS is a mandatory competence in the European curriculum of internal medicine, and specific training programs which cover applications in the domains of palliative care in acute care settings are available. Supervision, quality assurance and appropriate documentation are required. We expect that as the availability of mobile units suitable for point of care applications increases, these applications should become standard of care in the acute management of patients who require palliative care.
\end{abstract}

\section{Introduction}

\subsection{Why palliative care in the acute care settings?}

The combination of an ageing population with improving survival in malignant and non-malignant disease processes results in a growing cohort of the population who live with advanced or end-stage chronic diseases. Medical assessment may be necessary as a result of an acute decompensation, the failure of planned management strategies, or the requirement for levels of care that cannot be provided by skilled community nursing [1]. Acute medical evaluations, that take place in settings ranging from home visits, outpatient medical clinics or inpatient medical receiving units are pivotal moments in such situations, and the decisions made in these first interactions can alter the trajectory of patient care dramatically [1].

The incidence of patients with palliative care needs presenting to acute care settings is difficult to quantify [2], but it has been provocatively stated that acute care clinicians will likely encounter more palliative care situations than thoracotomies during their careers [3]. The American College of Emergency Physicians, in their recent Choosing Wisely strategy recommends engaging available palliative and hospice care services early after admission in patients who are likely to benefit [4]. This rapid engagement requires appropriate assessment and results not only in timely symptomatic relief, but also results in leveraging appropriate resources and setting goals of care [5]. It is essential that clinicians accept that end of life care is essential and

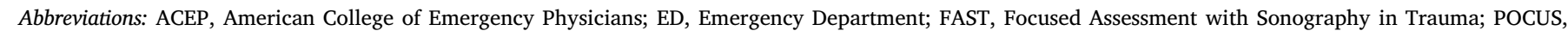
Point of Care Ultrasound; VTE, Venous Thromboembolism; WHO, World Health Organisation

* Corresponding author.

E-mail address: neal.breakey@spital-emmental.ch (N. Breakey). 
appropriate from the very beginning of a hospital stay [6].

In short, palliative care assessment should be available not only from the front door of our inpatient services, but also be a core component of our clinical decision-making toolkit when called to manage acute situations or new symptoms in the full breadth of healthcare settings.

\subsection{Why POCUS?}

Emergency care has historically been stereotyped as the identification and treatment of acute life-threatening problems. Although palliative care may be considered to be new to the formal curriculum of emergency medicine, in many domains the ultrasound skillset of a physician in acute medical care can be efficaciously deployed to the benefit of patients with both malignant and non-malignant disease processes that require palliative care, independent of context.

The use of Point of Care Ultrasonography (POCUS) has gained widespread acceptance as part of routine care in Emergency Medicine, Anaesthetics and Intensive Care, and can be defined as the use of an ultrasound system at the bedside of a patient to answer a focused clinical question or provide ultrasound guidance for an intervention. New developments in miniaturisation mean that these techniques can now also be extrapolated for use outside of inpatient settings, making point of care imaging available for home visits, hospice or community nursing facilities

The performance characteristics of POCUS make it an attractive diagnostic adjunct in acute palliative care. Common symptoms and palliative emergencies (differentiation of dyspnoea, bowel obstruction, urinary tract obstruction, venous thromboembolism) are highly amenable to diagnosis at the bedside. In addition, ultrasound is a useful adjunct in common palliative interventions (thoracentesis, paracentesis, difficult venous access, musculoskeletal interventions and regional anaesthesia). It is thus no surprise that patients who require palliative care value the time and expertise of clinicians performing POCUS, resulting in increased patient satisfaction [7]. Information gained from POCUS examinations in hospice settings or during home care can also provide useful information to assist discussions about diagnosis and prognosis [8,9], and the visual illustration of findings can be used to support joint decision-making [9].

A rational approach to cross-sectional imaging, in keeping with "Choosing Wisely" strategies is of significant importance [10]. However, it is important to recognise that palliative care does not mean "no care" [11] or "no imaging". Patients can sometimes be admitted with presumptive diagnoses based on symptoms and their underlying diagnosis, without imaging having been performed, because of a clinician's view that there are no further interventional consequences. The use of imaging in inpatient palliative care can be of substantive utility, prompting alterations in management a significant proportion of cases [12]. Providing comfort and support does not mandate an unmitigated "shift away from technologic care" [13]. We suggest that POCUS can elegantly fill a niche in a sometimes dichotomous approach to crosssectional imaging in patients with acute palliative care needs - addressing common and easily recognisable complications which can be missed even if other imaging tools are not used.

In this review we focus on the use of POCUS by a member of an interdisciplinary team at the bedside of the patient requiring palliative care, and provide a set of applications (both diagnostic, and therapeutic) for daily use in acute care situations. We suggest that POCUS has the potential to streamline further diagnostic strategies and interventions without necessitating patient transfer, optimise inpatient length of stay, expedite timely symptomatic relief and reduce complications from specific palliative interventions.

\section{Acute diagnostics}

\subsection{Abdominal pain}

\subsubsection{Bowel obstruction}

Acute or subacute obstruction occurs in patients who have advanced intra-abdominal or pelvic malignancies with an estimated prevalence of $2 \%$ [14]. Demonstrating obstruction is significant not only because of the need for timely targeted symptomatic treatment, but is also prognostically important, with a 6-month life expectancy of approximately $50 \%$ where operable, and $8 \%$ with inoperable obstruction [15].

Abdominal plain films are frequently used as a first line investigation for bowel obstruction, however the diagnostic performance of POCUS in mixed aetiologies is favourable in comparison to conventional radiography studies when performed not only by radiologists [16], but also the treating clinicians [17-20]. POCUS can also be performed without having to move patients from their current setting of care and without contrast administration. The resulting diagnosis can allow timely medical palliation to be undertaken or direct the need for further cross-sectional imaging. We therefore consider POCUS the most appropriate first line test.

When considering the possibility of bowel obstruction in a patient in with inoperable metastatic peritoneal disease, the contextual and pragmatic use of POCUS to give timely, and often "just enough" clinical information at the bedside to inform further care without movement to other clinical settings is arguably unique to palliative care. In patients with no known intra-abdominal malignancy, it is rarely appropriate that the diagnostic cascade ceases after a single POCUS examination, especially in outpatient settings.

Typical sonographic findings include dilated small bowel loops, as demonstrated in Fig. 1, "to and fro" peristalsis with obstruction, the absence of peristalsis in paralytic ileus, or a collapsed colonic lumen.

\subsubsection{Urinary tract obstruction}

In addition to lower abdominal and flank pain, urinary tract obstruction carries significant prognostic significance in many malignancies and left untreated exposes the patient to an infection risk or, in cases of bilateral obstruction, progressive renal failure [21].

Measurement of residual urinary volumes is often one of the first interactions that junior medical staff have with ultrasound. A focused examination of the urinary tract including assessment of the upper urinary tract can provide rapid diagnostic information in cases of lower abdominal pain or renal failure.Urine volumes measured with ultrasound and with a bladder catheter are highly correlated [22] and with appropriate training clinicians can achieve competence in assessing hydronephrosis [23-25] with a diagnostic performance similar to radiologists [26].

With the availability of a quick and relatively simple intervention such as urinary catheterisation, there is potential to reduce the time to symptomatic relief. lower urinary tract ultrasound has been described within the hospice setting following specific training, reducing the need for patient transfer when lower urinary tract obstruction is suspected [27].

Although the aetiology of upper urinary tract obstruction may not be obvious in a point of care examination, being able to demonstrate hydronephrosis early in the patients stay can streamline the further diagnostics and guide the need for further cross-sectional imaging or intervention such as palliative percutaneous nephrostomy (with ultrasound guidance as an alternative to fluoroscopic techniques), ultrasound guided suprapubic cystostomy or ureteric stenting.

In a focused exam the renal parenchyma and pelvis are evaluated in two planes, transverse and longitudinally, to assess for hydronephrosis, represented by an echo-free dilatation of the renal pelvis, and two views of the bladder should be obtained to assess bladder volume as illustrated in Fig. 2. 


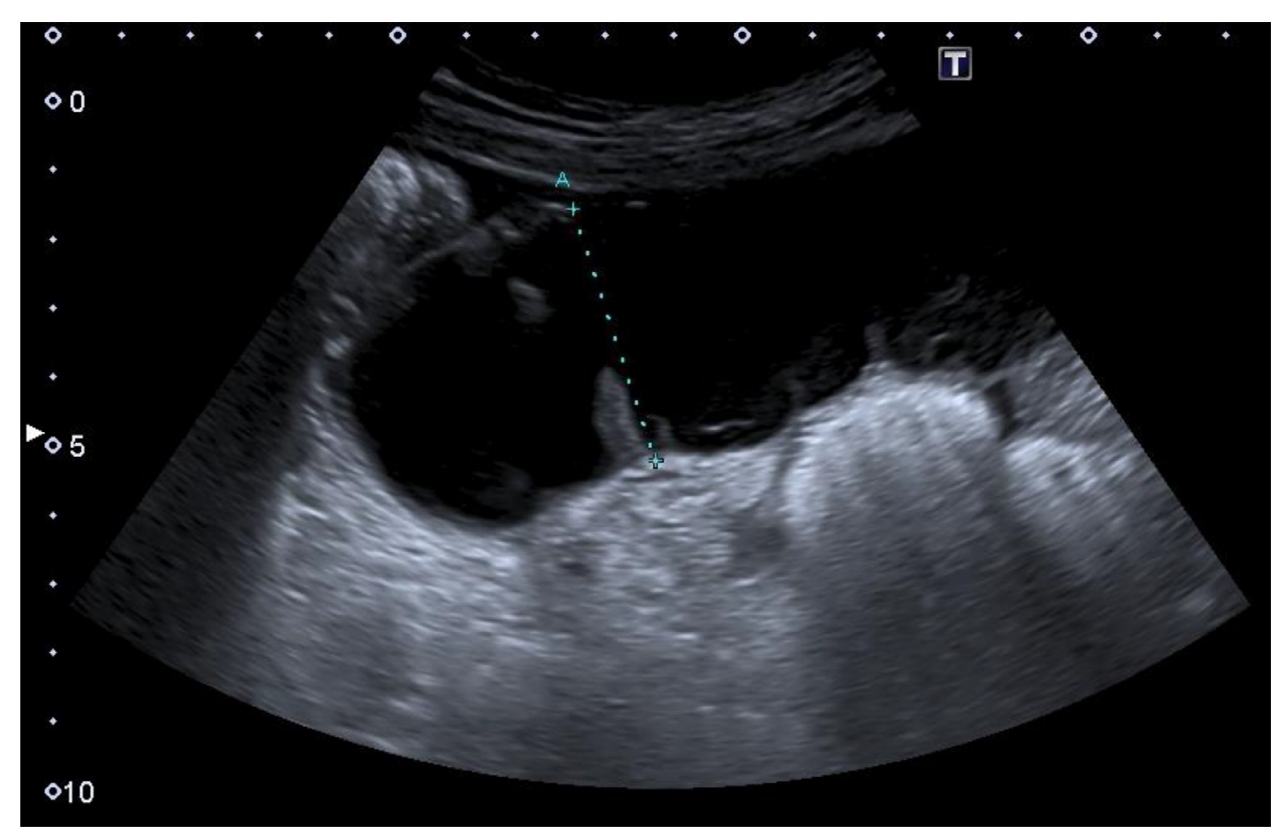

Fig. 1. Image demonstrating dilated small bowel loops $(>2 \mathrm{~cm})$ and interenteric fluid.

\subsection{Differentiation of dyspnoea}

The necessity of palliative care input in non-malignant disease has gained widespread recognition [28-30], although appropriate early referral to palliative care services occurs less frequently than it should [31]. Acute decompensation of chronic lung disease and chronic heart failure are common reasons for presentation and early diagnostic input with POCUS can lead to early identification of the presenting complaint and treatment in common diagnostic conundrums.

There is now a significant body of evidence to suggest the utility of focused thorax ultrasound in the differentiation of dyspnoea - congestive heart failure [32], pneumonia [33,34], pleural effusion [35,36], pneumothorax [37] and descriptions of typical findings suggestive of pulmonary embolism [38,39] and radiotherapy induced pneumonitis [40,41]. Relying purely on clinical signs to diagnose cardiac tamponade is challenging, and a subxiphoid view on focused cardiac ultrasound can aid diagnosis of malignant pericardial effusions [42].

These studies from predominantly mixed populations in acute medical care settings show promising performance characteristics. The performance of diagnostic pulmonary POCUS is however demanding, particularly in patients with pre-existing lung disease. The examination of the peripheral lung structures can provide useful amounts of information, but central localised malignant processes require complementary imaging strategies [43].
In a focused lung examination, the pleural interface is examined in multiple locations examining specific changes either to the pleura themselves (subpleural consolidations, pleural thickening or specific pleural artefacts), the pleural space (pleural effusion) or absence of typical pleura motion (pneumothorax). Fig. 3 demonstrates the typical reverberations artefacts found in pulmonary oedema, pneumonia and pleural effusions.

\subsection{Complications of malignancy: venous thromboembolism}

Malignancy is an independent risk factor for venous thromboembolism (VTE), has negative prognostic implications, and in addition the additional morbidity, VTE results in higher healthcare costs [44]. In some settings patients may be reluctant to undergo further cross-sectional Imaging, either because of previous negative experiences (for example claustrophobia), or wish no further complex diagnostics as part of their palliative care. In such situations the use of a bedside test that is non-invasive is highly attractive. In a population where renal failure would further increase morbidity, avoiding the use of contrast with either compression sonography or lung ultrasound means that the desire for accurate diagnostic information does not necessarily have to include the risk of intravenous contrast.

The ESC Guidelines for Pulmonary Embolism recommends that lower limb compression ultrasound can be considered as a first line
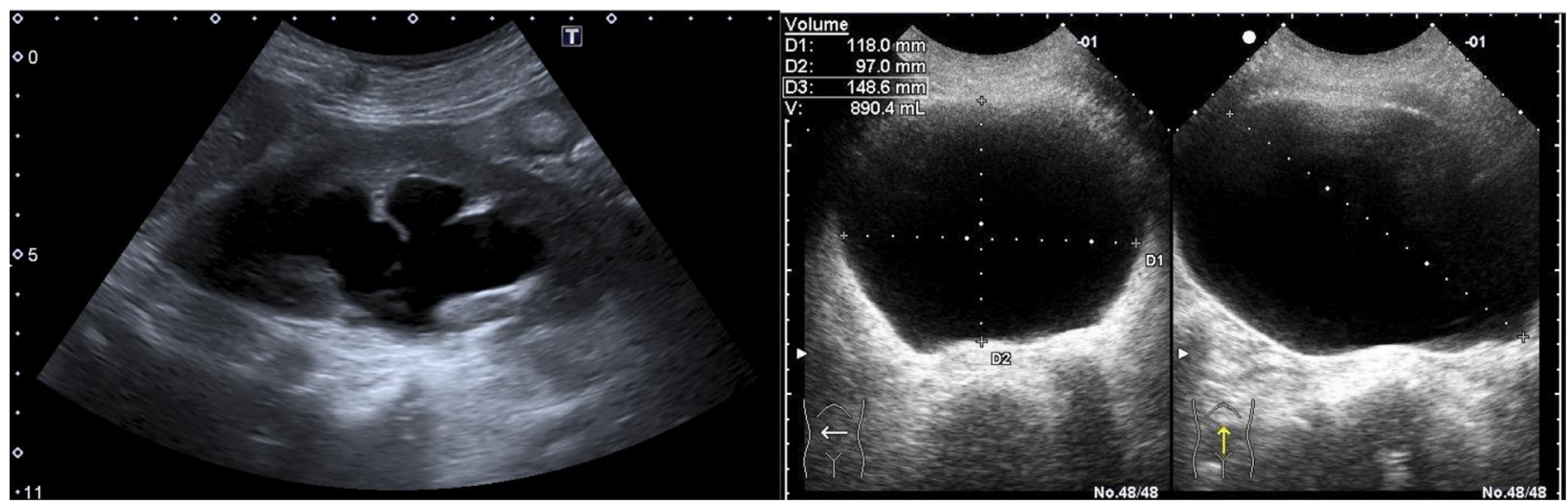

Fig. 2. Image demonstrating Hydronephrosis and measurement of bladder volume. 


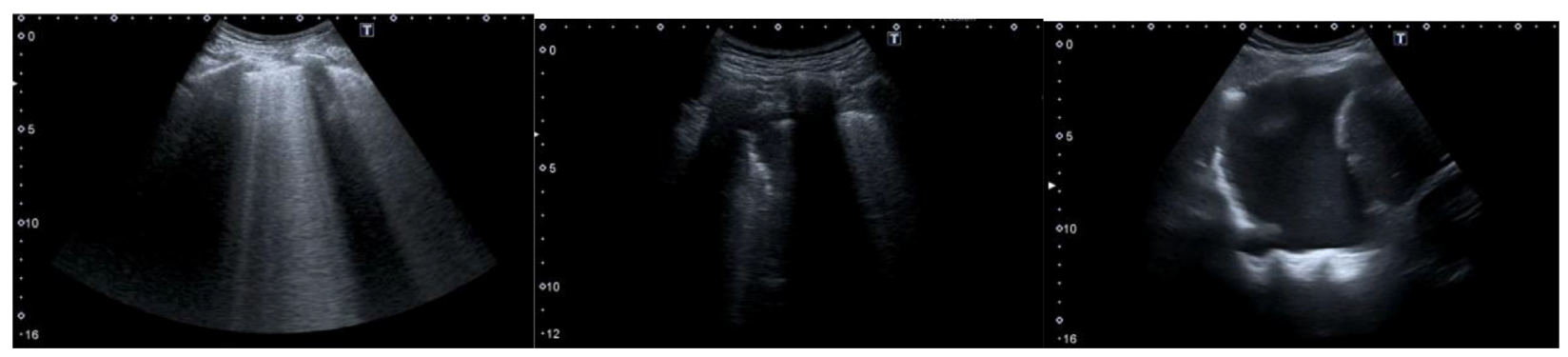

Fig. 3. Image demonstrating typical LUS Findings (B-line profile, subpleural consolidation, pleural effusion).

investigation and further imaging testing is obviated if the result is positive (Evidence Level I A [45]). A POCUS-first diagnostic strategy with either compression sonography or lung ultrasound can allow further imaging to be streamlined or targeted, or potentially avoided. When pulmonary embolism is diagnosed, focused cardiac ultrasound for detection of right ventricular dysfunction is recommended as part of the risk stratification for selection of management strategies [45].

Focused compression ultrasonography has been used by both doctors [8] and nurses [46] to diagnose thromboembolic complications in hospice care settings.

Focused compression ultrasonography of the lower limb veins is typically performed at the level of the common femoral vein and the popliteal vein by using compression to occlude a hypoechogenic venous lumen as demonstrated in Fig. 4. In cases of deep venous thromboembolism, the venous lumen is non-compressible.

\section{Palliative interventions}

\subsection{Ultrasound guided thoracentesis}

Malignant pleural effusions is a common cause of dyspnoea in patients with malignant disease, with a post-mortem series suggesting pleural effusions occurring in $15 \%$ of patients who died with malignancies [47]. Clinical and conventional radiographs have limited diagnostic performance in comparison to ultrasound when establishing whether a pleural effusion is present, and in estimating volume $[36,48]$.

When thoracentesis is appropriate, ultrasound guidance in mixed populations demonstrates a reduction in post-interventional pneumothorax $[49,50]$, and reduces the rates of "dry taps" in pleural effusions that obliterate less than half of the hemidiaphragm. Current guidelines strongly recommend the use of thoracic ultrasound guidance for all pleural procedures [51]. The increasing availability of point of care ultrasound devices means that a trip to the radiology department is

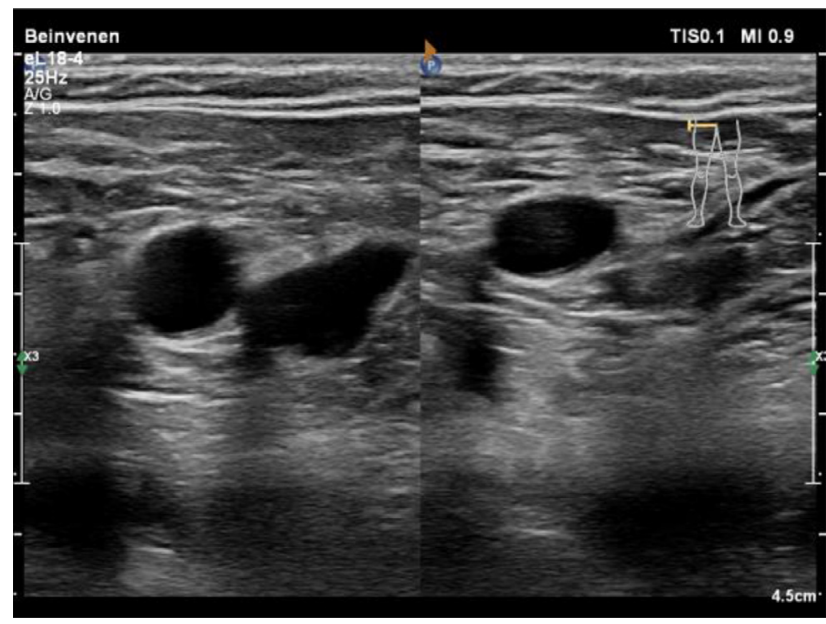

Fig. 4. Image demonstrating 2-Point compression ultrasonography with normal compression of Vena femoralis communis. no longer required for "x marks the spot" pre-procedural marking [52] and a reduction in length of stay [53] has been described.

Palliative thoracentesis with POCUS guidance can be performed on an outpatient basis and has been reported to be cost-effective [54]. In cases where repeated aspiration is required, tunneled indwelling pleural catheters can be considered, although the risks and benefits of this invasive intervention must be considered in each individual patient [55].

The classically described infracostal path of the intercostal artery has been demonstrated to show significant anatomical variation, particularly on the posterior aspect of the chest [56], but POCUS can adequately screen for these vulnerable puncture sites [57].

Multiple methods of quantification exist, but one of the most usable is the Balik formula [48] where a transverse view is obtained at the posterior axillary line and the maximum distance between parietal and visceral pleura recorded in millimeters (as demonstrated in Fig. 5). This value is multiplied by 20 to give an estimate of pleural effusion volume in milliliters.

Having successfully completed the procedure, a further ultrasound examination can exclude an iatrogenic pneumothorax. In a further novel development of ultrasound guidance there are emerging reports of the use of intracavitary contrast-enhanced ultrasound to assess complex effusion, potentially allowing optimal drainage of loculated effusions [58].

\subsection{Ultrasound guided paracentesis}

The symptoms associated with malignant ascites can be debilitating, resulting in a significant reduction in quality of life, however intervention with paracentesis provides a measurable symptomatic improvement [59]. The presence of ascites has not only diagnostic but also prognostic implications [60].

Clinical examination alone demonstrates poor performance for detecting ascites (sensitivity and specificity ranging from 50 to $94 \%$ and 29 to $82 \%[61,62]$ in mixed aetiologies), and cannot reliably predict a

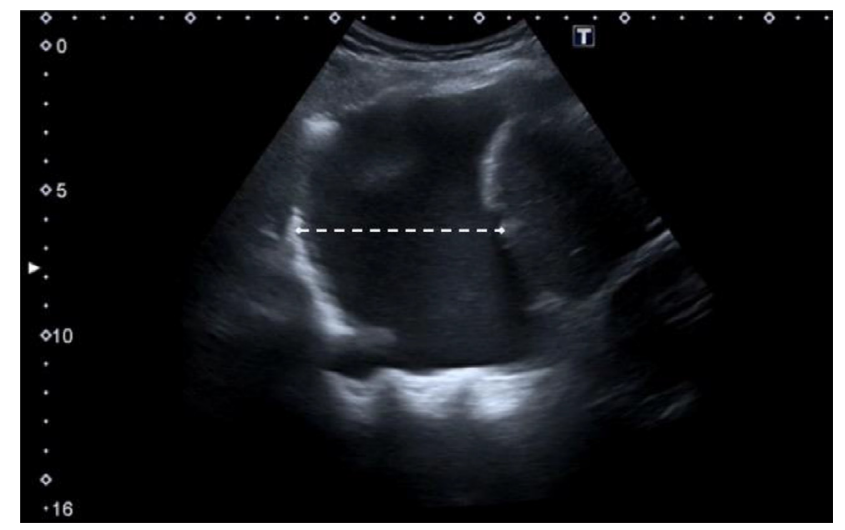

Fig. 5. Assessment of pleural effusion volume prior to thoracentesis, measuring pleural-diaphragm distance for use with the Balik formula. 
safe area for puncture [63]. Demonstrating ascites and selecting a safe site for puncture builds on the core skills developed while learning the FAST scan and is recommended by the Society of Hospital Medicine [64].

A retrospective review in a mixed group of patients demonstrated an association between ultrasound use and a reduction in adverse events and length of stay [65].

Implementation of a POCUS imaging strategy on admission to a hospice smoothed the 'patient journey' by limiting the number of interdepartmental visits and reduced patients' length of stay [8]. It is also feasible to perform ultrasound assisted paracentesis in patients' homes $[8,9]$, and can be performed in outpatient settings [27]. POCUS at home can not only obviate the transfer and admission for patients with symptomatic ascites, but can also avoid futile transfer when no paracentesis is required [13].

While critique exists of the sensitivity of FAST scanning in cardiopulmonary stable patients after high energy trauma in an era of near ubiquitous CT-availability [66] and there is significant potential to develop further ultrasound diagnostic imaging strategies in trauma settings [67], the same technique is a high value strategy in rapidly identifying those who can benefit from ascitic drainage.

\subsection{Ultrasound guided venous access}

Periprocedural pain during vascular access is frequently reported, often undertreated [68], and repeated attempts can lead to hyperalgesia [69]. In palliative care this can be further complicated by long hospital stays and multiple IV therapies, and the veno-toxic effects of chemotherapy. The use of ultrasound to assist in venous access has been demonstrated to increase the likelihood of successful cannulation in patients with difficult peripheral venous access [70] with being solely related to vessel characteristics rather than patient characteristics [71], although not necessarily reducing the time to achieve definitive vascular access, or the number of percutaneous puncture [72,73]. The sinking costs of devices with a single linear high-frequency probe means that access to these skills across the entire interdisciplinary team is now a possibility and an adjunct that is appreciated by patients [72,74].

Our practice, in keeping with the recommendations of the Society for Hospital Medicine [75], is to use a linear high-frequency probe for ultrasound guided access using the in-plane or out-of-plane technique after two or more attempts, or when a patient is known to have difficult peripheral access.

\subsection{Ultrasound guided analgesic strategies}

The use of interventional techniques to manage pain in acute care has become commonplace. From local anaesthesia for laceration repair to more complex interventions for radicular pain or analgesia following hip fracture, these strategies are valuable adjuncts to the WHO Analgesic ladder. These skills are also transferable to the treatment of cancer related pain. Isolated ultrasound guided peripheral nerve blocks have been described to deliver adequate palliative analgesia over single dermatomes [76]. Tissue-plane blocks and plexus blocks also show promise for pain after both specific interventions and for neuropathic or metastatic bone pain which is not adequately controlled with oral analgesia [77]. Depending on local skillsets it may be possible for some of these more advanced techniques to be implemented by clinicians, or in collaboration with local Pain Teams or Anaesthetic Departments.

The presence of arthritis is an independent predictor of the prevalence of significant pain in the last months of life, independent of the terminal disease category of the patient. The prevalence of pain appears to increase particularly during the last 4 months of life [78]. Musculoskeletal pain may be overlooked as may be not related to the case of death, but can still cause significant pain and impairment in a dying person [79]. In this context POCUS can reliably identify long bone fractures [80], rib fractures [81] and joint effusions [82], although specific diagnostic evidence for patients with malignant disease is lacking.

Opiate analgesia may not be able to provide reliable long term analgesia in chronic non-cancer pain without adverse effects such as constipation, nausea or somnolence [83]. Arthrocentesis and corticosteroid and local anaesthetic infiltrations performed under ultrasound guidance can provide symptomatic relief in this context, and is associated with less procedural pain, improved arthrocentesis success, greater synovial fluid yield, and more complete joint decompression, and the complications of systemic steroid treatment can be avoided $[84,85]$.

\section{Implementation}

POCUS is a mandatory competency in the European Curriculum of Internal Medicine [86] and although specific training programs for ultrasound in palliative care are not currently available, internationally single "Palliative POCUS" courses have been run $[87,88]$. Locally, in Switzerland, the recently created POCUS Certificate of Competency in Ultrasound [89] covers the core material in this review and the qualification is open to all board-qualified providers. Given the significant overlap between the POCUS skills required for palliative care and that provided by generic acute medical POCUS training courses consisting of theme-specific theoretical and practical modules, courses of this nature may be considered to be reasonable training options in line with the recommendations of the Ultrasound Working Group of the European Federation of Internal Medicine [90].

Completing a course is a first step in gaining competencies. Performance characteristics improve with practice and supervision, as demonstrated between the differences in the performance characteristics of fellowship trainees and other providers when assessing for hydronephrosis [23]. Maintaining skills learned on the courses does require continued local mentoring, adequate image and report documentation and retention and well as an established process for quality assurance of diagnostics [90].

Recent developments in hardware and software mean that the initial hardware costs of an ultrasound system have significantly declined over recent years. The majority of techniques described in this review can be performed with a combination a low-frequency curvilinear probe and a high-frequency linear ultrasound probe.

\section{Limitations and further research}

Specific descriptions of POCUS in palliative care are limited to case reports and case series, and there is a sparsity of focused prospective research in this patient population. We suggest that basic binary decision making, for example with urinary tract obstruction or ascites, can be supported by analogous literature from more mixed populations. However, it is clear that research to examine POCUS-first diagnostic strategies assessing more complex questions in this population is sparse. Small case series demonstrate opportunities for more thorough health economic evaluation $[8,54,91]$ of a POCUS-led strategy.

Innovative research in other POCUS fields has begun to examine clinical endpoints such as diagnostic performance, but also mortality and rates of intervention [92]. Similar research assessing patient orientated outcomes related to POCUS use in acute palliative care, such as peri-interventional pain, requirement for transfer of location, readmission, or improvement of symptoms is required.

\section{Conclusion}

In summary we suggest the targeted use of POCUS for palliative care in acute medical care can improve clinical outcomes by reducing complications and inappropriate care, facilitating and streamlining diagnostic processes at the bedside. This has the potential to be achieved with minimal interruption to the patient without the need for 
movement to another clinical setting. POCUS can be performed by a patient-known and trusted professional who is already aware of the surrounding clinical context. As the capital costs required to obtain and maintain Ultrasound equipment decrease, and as the increasing availability of mobile units ideally suited to Point-of-Care use increases, we expect that the above applications should become part of the standard of care in the acute management of patients who require palliative care.

\section{Funding}

No funding for the present work was received.

\section{Ethics approval and consent to participate}

Not applicable.

\section{Patient consent for publication}

Not applicable.

\section{Previous presentation}

No previous presentation or publication of manuscript.

\section{Authorship contributions statement}

NB conceived and designed the review and drafted the manuscript. BL, TCS, JO and GM critically revised the manuscript. NB and BL provided the illustrative examples. All authors approved the final version of the manuscript and agree to be accountable for all aspects of the work.

\section{Declaration of Competing Interest}

$\mathrm{NB}, \mathrm{JO}, \mathrm{BL}$ and GM report no competing interests. TCS has received research grants and lecture fees from Bayer, Boehringer Ingelheim, and Daiichi-Sankyo as well as the Gottfried and Julia Bangerter Rhyner Foundation.

\section{References}

[1] Grudzen CR, Stone SC, Morrison RS. The palliative care model for emergency department patients with advanced illness. J Palliat Med 2011;14:945-50. https://doi org/10.1089/jpm.2011.0011.

[2] Wong J, Gott M, Frey R, Jull A. What is the incidence of patients with palliative care needs presenting to the Emergency Department? A critical review. Palliat Med 2014;28:1197-205. https://doi.org/10.1177/0269216314543318.

[3] Hughes J. Palliative care in emergency medicine: a perennial skill with a new emphasis. CJEM 2019;21:163-4. https://doi.org/10.1017/cem.2019.7.

[4] American College of Emergency Physicians: Don't delay engaging available palliative and hospice care services in the emergency department for patients likely to benefit. 14 Oct2013[cited 20 May 2019]. Available: http://www.choosingwisely. org/clinician-lists/american-college-emergency-physicians-delaying-palliative-andhospice-care-services-in-emergency-department/.

[5] Wang DH. Beyond code status: palliative care begins in the emergency department. Ann Emerg Med 2017;69:437-43. https://doi.org/10.1016/j.annemergmed.2016. 10.027.

[6] Dawood M. End of life care in the emergency department. Emerg Med J 2019. https://doi.org/10.1136/emermed-2019-208632. emermed-2019-208632.

[7] Jones T, Groves K. P155 Making sense of shades of grey!: impact of hospice ultrasound use on patient care. BMJ Support Palliat Care 2013;3. https://doi.org/10. 1136/bmjspcare-2013-000591.177. A65.1-A65.

[8] Gishen F, Trotman I. Bedside ultrasound - experience in a palliative care unit. Eur J Cancer Care 2009;18:642-644.. https://doi.org/10.1111/j.1365-2354.2009. 01071.x.

[9] Landers A, Ryan B. The use of bedside ultrasound and community-based paracentesis in a palliative care service. J Prim Health Care 2014;6:148-51 Available https://www.ncbi.nlm.nih.gov/pubmed/24892133.

[10] Rao VM, Levin DC. The overuse of diagnostic imaging and the Choosing Wisely initiative. Ann Intern Med 2012;157:574-6. https://doi.org/10.7326/0003-4819. 157-8-201210160-00535.

[11] Dean AJ, Melniker LA. Hospice and palliative medicine ultrasound: a new horizon for emergency medicine? Acad Emerg Med 2010;17:330-2. https://doi.org/10. 1111/j.1553-2712.2010.00688.x

[12] Grant MP, Cardin A, OConnor N, Eastman P. Examining clinical utility of imaging for inpatient palliative care. Am J Hospice Palliative Med 2016. https://doi.org/10. 1177/1049909116640524. [cited 7 Jul 2017].

[13] Mariani PJ, Setla JA. Palliative ultrasound for home care hospice patients. Acad Emerg Med 2010;17:293-6. https://doi.org/10.1111/j.1553-2712.2009.00678.x.

[14] Ferguson HJM, Ferguson CI, Speakman J, Ismail T. Management of intestinal obstruction in advanced malignancy. Ann Med Surg (Lond) 2015;4:264-70. https:// doi.org/10.1016/j.amsu.2015.07.018.

[15] Tuca A, Guell E, Martinez-Losada E, Codorniu N. Malignant bowel obstruction in advanced cancer patients: epidemiology, management, and factors influencing spontaneous resolution. Cancer Manag Res 2012:159. https://doi.org/10.2147/ CMAR.S29297.

[16] Suri S, Gupta S, Sudhakar PJ, Venkataramu NK, Sood B, Wig JD. Comparative evaluation of plain films, ultrasound and CT in the diagnosis of intestinal obstruction. Acta Radiol 1999;40:422-8 Available https://www.ncbi.nlm.nih.gov/ pubmed/10394872.

[17] Jang TB, Schindler D, Kaji AH. Bedside ultrasonography for the detection of small bowel obstruction in the emergency department. Emerg Med J 2011;28:676-8. https://doi.org/10.1136/emj.2010.095729.

[18] Ünlüer E.E., Yavaşi Ö, Eroğlu O., Yilmaz C., Akarca F.K. Ultrasonography by emergency medicine and radiology residents for the diagnosis of small bowel obstruction: Eur J Emerg Med. 2010;17: 260-4. doi:10.1097/MEJ. 0b013e328336c736.

[19] Frasure S. Accuracy of abdominal ultrasound for the diagnosis of small bowel obstruction in the emergency department. World J Emerg Med 2018;9:267. https:// doi.org/10.5847/wjem.j.1920-8642.2018.04.005.

[20] Gottlieb M, Peksa GD, Pandurangadu AV, Nakitende D, Takhar S, Seethala RR. Utilization of ultrasound for the evaluation of small bowel obstruction: a systematic review and meta-analysis. Am J Emerg Med 2018;36:234-42. https://doi.org/10. 1016/j.ajem.2017.07.085.

[21] Prentice J, Amer T, Tasleem A, Aboumarzouk O. Malignant ureteric obstruction decompression: how much gain for how much pain? A narrative review. J R Soc Med 2018;111:125-35. https://doi.org/10.1177/0141076818766725.

[22] D'Silva KA, Dahm P, Wong CL. Does this man with lower urinary tract symptoms have bladder outlet obstruction?: the rational clinical examination: a systematic review. JAMA 2014;312:535. https://doi.org/10.1001/jama.2014.5555.

[23] Herbst M, Rosenberg G, Daniels B, Gross C, Singh D, Molinaro A, et al. Accuracy of point-of-care ultrasound for hydronephrosis in patients with suspected renal colic: a look at emergency providers with variable ultrasound experience. Ann Emerg Med 2013;62:S32-3. https://doi.org/10.1016/j.annemergmed.2013.07.369.

[24] Mandavia DP, Aragona J, Chan L, Chan D, Henderson SO. Ultrasound training for emergency physicians-a prospective study. Acad Emerg Med 2000;7:1008-1014. Available https://www.ncbi.nlm.nih.gov/pubmed/11043996.

[25] Pathan SA, Mitra B, Mirza S, Momin U, Ahmed Z, Andraous LG, et al. Emergency physician interpretation of point-of-care ultrasound for identifying and grading of hydronephrosis in renal colic compared with consensus interpretation by emergency radiologists. Acad Emerg Med 2018;25:1129-37. https://doi.org/10.1111/ acem.13432.

[26] Smith-Bindman R, Aubin C, Bailitz J, Bengiamin RN, Camargo CA, Corbo J, et al. Ultrasonography versus computed tomography for suspected nephrolithiasis. N Engl J Med 2014;371:1100-10. https://doi.org/10.1056/NEJMoa1404446.

[27] Nemeth E, Cate W, Sharon C. Ultrasound scanning in a hospice setting - does it really alter patient pathways? BMJ Support Palliat Care 2011;1:224. https://doi org /10.1136/bmjspcare-2011-000105.60.

[28] WHO Global Atlas of Palliative Care. [cited 14 Aug2017]. Available: http://www who.int/nmh/Global_Atlas_of_Palliative_Care.pdf.

[29] Traue DC. Palliative care in non-malignant diseases. J R Soc Med 2005;98:503-6. https://doi.org/10.1258/jrsm.98.11.503.

[30] Siouta N, van Beek K, Preston N, Hasselaar J, Hughes S, Payne S, et al. Towards integration of palliative care in patients with chronic heart failure and chronic obstructive pulmonary disease: a systematic literature review of European guidelines and pathways. BMC Palliat Care 2016:15. https://doi.org/10.1186/s12904016-0089-4.

[31] Lipinski M, Eagles D, Fischer LM, Mielniczuk L, Stiell IG. Heart failure and palliative care in the emergency department. Emerg Med J 2018;35:726-9. https://doi.org/ 10.1136/emermed-2017-207186.

[32] Pivetta E, Goffi A, Nazerian P, Castagno D, Tozzetti C, Tizzani P, et al. Lung ultrasound integrated with clinical assessment for the diagnosis of acute decompensated heart failure in the emergency department: a randomized controlled trial. Eur J Heart Fail 2019. https://doi.org/10.1002/ejhf.1379.

[33] Long L, Zhao H-T, Zhang Z-Y, Wang G-Y, Zhao H-L. Lung ultrasound for the diagnosis of pneumonia in adults: a meta-analysis. Medicine (Baltimore) 2017;96:e5713. https://doi.org/10.1097/MD.0000000000005713.

[34] Orso D, Guglielmo N, Copetti R. Lung ultrasound in diagnosing pneumonia in the emergency department: a systematic review and meta-analysis. Eur J Emerg Med 2017. https://doi.org/10.1097/MEJ.0000000000000517.

[35] Soni NJ, Franco R, Velez MI, Schnobrich D, Dancel R, Restrepo MI, et al. Ultrasound in the diagnosis and management of pleural effusions: ultrasound and Pleural Effusions. J Hosp Med 2015;10:811-6. https://doi.org/10.1002/jhm.2434.

[36] Yousefifard M, Baikpour M, Ghelichkhani P, Asady H, Nia KS, Jafari AM, et al. Screening performance characteristic of ultrasonography and radiography in detection of pleural effusion; a meta-analysis. Emergency 2018;4:1-10.

[37] Lichtenstein D, Mezière G, Biderman P, Gepner A. The "lung point": an ultrasound sign specific to pneumothorax. Intensive Care Med 2000;26:1434-40 Available https://www.ncbi.nlm.nih.gov/pubmed/11126253. 
[38] Mathis G, Blank W, Reißig A, Lechleitner P, Reuß J, Schuler A, et al. Thoracic ultrasound for diagnosing pulmonary embolism. Chest 2005;128:1531-8. https:// doi.org/10.1378/chest.128.3.1531.

[39] Nazerian P, Vanni S, Volpicelli G, Gigli C, Zanobetti M, Bartolucci M, et al. Accuracy of point-of-care multiorgan ultrasonography for the diagnosis of pulmonary embolism. Chest 2014;145:950-7. https://doi.org/10.1378/chest.13-1087.

[40] Petruzzelli MF, Vasti MP, Tramacere F, D'Errico MP, Gianicolo EAL, Andreassi MG, et al. The potential role of lung ultrasound B-lines for detection of lung radio-induced toxicity in breast cancer patients after radiation therapy. Echocardiography 2016;33:1374-80. https://doi.org/10.1111/echo.13249.

[41] Petruzzelli MF, Vasti MP, Errico A, D'Agostino R, Tramacere F, Gianicolo EAL, et al. Ultrasound B-lines for detection of late lung fibrosis in breast cancer patients after radiation therapy. Ann Ist Super Sanita 2018. https://doi.org/10.4415/ANN_18_04_ 05. [cited 26 Feb 2019].

[42] Nagdev A, Stone MB. Point-of-care ultrasound evaluation of pericardial effusions: does this patient have cardiac tamponade? Resuscitation 2011;82:671-3. https:// doi.org/10.1016/j.resuscitation.2011.02.004.

[43] Reissig A, Copetti R. Lung ultrasound in community-acquired pneumonia and in interstitial lung diseases. Respiration 2014;87:179-89. https://doi.org/10.1159/ 000357449 .

[44] Ay C, Pabinger I, Cohen AT. Cancer-associated venous thromboembolism: burden, mechanisms, and management. Thromb Haemost 2017;117:219-30. https://doi. org/10.1160/TH16-08-0615.

[45] Konstantinides SV, Meyer G, Becattini C, Bueno H, Geersing G-J, Harjola V-P, et al. 2019 ESC guidelines for the diagnosis and management of acute pulmonary embolism developed in collaboration with the European Respiratory Society (ERS). Eur Heart J 2020;41:543-603. https://doi.org/10.1093/eurheartj/ehz405.

[46] White C, Noble SIR, Watson M, Swan F, Allgar VL, Napier E, et al. Prevalence, symptom burden, and natural history of deep vein thrombosis in people with advanced cancer in specialist palliative care units (HIDDen): a prospective longitudinal observational study. Lancet Haematol 2019;6:e79-88. https://doi.org/10. 1016/S2352-3026(18)30215-1.

[47] Rodrîguez-Panadero F, Borderas Naranjo F, López Mejîas J. Pleural metastatic tumours and effusions. Frequency and pathogenic mechanisms in a post-mortem series. Eur Respir J 1989;2:366-9 Available https://www.ncbi.nlm.nih.gov/ pubmed/2786818.

[48] Balik M, Plasil P, Waldauf P, Pazout J, Fric M, Otahal M, et al. Ultrasound estimation of volume of pleural fluid in mechanically ventilated patients. Intensive Care Med 2006;32:318-21. https://doi.org/10.1007/s00134-005-0024-2.

[49] Gordon CE. Pneumothorax following thoracentesis: a systematic review and metaanalysis. Arch Intern Med 2010;170:332. https://doi.org/10.1001/archinternmed. 2009.548.

[50] Jones PW, Moyers JP, Rogers JT, Rodriguez RM, Lee YCG, Light RW. Ultrasoundguided thoracentesis: is it a safer method? Chest 2003;123:418-23 Available https://www.ncbi.nlm.nih.gov/pubmed/12576360.

[51] Havelock T, Teoh R, Laws D, Gleeson F. on behalf of the BTS Pleural Disease Guideline Group. Pleural procedures and thoracic ultrasound: British Thoracic Society pleural disease guideline 2010. Thorax 2010;65:i61-76. https://doi.org/10. 1136/thx.2010.137026.

[52] Raptopoulos V, Davis LM, Lee G, Umali C, Lew R, Irwin RS. Factors affecting the development of pneumothorax associated with thoracentesis. Am J Roentgenol 1991;156:917-20. https://doi.org/10.2214/ajr.156.5.2017951.

[53] Hannan LM, Steinfort DP, Irving LB, Hew M. Direct ultrasound localisation for pleural aspiration: translating evidence into action: ultrasound for pleural aspiration. Intern Med J 2014;44:50-6. https://doi.org/10.1111/imj.12290.

[54] Segaline N, Wang J, Bethancourt B, Ota KS. The role of ultrasound-guided therapeutic thoracentesis in an outpatient transitional care program: a case series. Am J Hosp Palliat Care 2019;36:927-31. https://doi.org/10.1177/1049909119837517.

[55] Beyea A, Winzelberg G, Stafford RE. To drain or not to drain: an evidence-based approach to palliative procedures for the management of malignant pleural effusions. J Pain Symptom Manage 2012;44:301-6. https://doi.org/10.1016/j. jpainsymman.2012.05.002.

[56] Salamonsen M, Ellis S, Paul E, Steinke K, Fielding D. Thoracic ultrasound demonstrates variable location of the intercostal artery. Respiration 2012;83:323-9. https://doi.org/10.1159/000330920.

[57] Salamonsen M, Dobeli K, McGrath D, Readdy C, Ware R, Steinke K, et al. Physicianperformed ultrasound can accurately screen for a vulnerable intercostal artery prior to chest drainage procedures: ultrasound imaging of intercostal artery. Respirology 2013;18:942-7. https://doi.org/10.1111/resp.12088.

[58] Deganello A, Rafailidis V, Sellars ME, Ntoulia A, Kalogerakou K, Ruiz G, et al. Intravenous and intracavitary use of contrast-enhanced ultrasound in the evaluation and management of complicated pediatric pneumonia: contrast-enhanced US in complicated pediatric pneumonia. J Ultrasound Med 2017;36:1943-54. https://doi. org/10.1002/jum.14269.

[59] Easson AM, Bezjak A, Ross S, Wright JG. The ability of existing questionnaires to measure symptom change after paracentesis for symptomatic ascites. Ann Surg Oncol 2007;14:2348-57. https://doi.org/10.1245/s10434-007-9370-3.

[60] Ayantunde A, Parsons S. Pattern and prognostic factors in patients with malignant ascites: a retrospective study. Ann Oncol 2007;18:945-9. https://doi.org/10.1093/ annonc/mdl499.

[61] Cattau EL. The accuracy of the physical examination in the diagnosis of suspected ascites. JAMA 1982;247:1164. https://doi.org/10.1001/jama.1982. 03320330060027.

[62] Williams JW, Simel DL. The rational clinical examination. Does this patient have ascites? How to divine fluid in the abdomen. JAMA 1992;267:2645-8 Available https://www.ncbi.nlm.nih.gov/pubmed/1573754.
[63] Bard C, Lafortune M, Breton G. Ascites: ultrasound guidance or blind paracentesis? CMAJ 1986;135:209-10 Available http://www.ncbi.nlm.nih.gov/pmc/articles/ PMC1491159/.

[64] Cho J, Jensen TP, Rierson K, Matthews BK, Bhagra A, Franco-Sadud R, et al. Recommendations on the use of ultrasound guidance for adult abdominal paracentesis: a position statement of the society of hospital medicine. J Hosp Med 2019;14:E7-15. https://doi.org/10.12788/jhm.3095.

[65] Patel PA, Ernst FR, Gunnarsson CL. Evaluation of hospital complications and costs associated with using ultrasound guidance during abdominal paracentesis procedures. J Med Econ 2012;15:1-7. https://doi.org/10.3111/13696998.2011.628723.

[66] Stengel D, Leisterer J, Ferrada P, Ekkernkamp A, Mutze S, Hoenning A. Point-ofcare ultrasonography for diagnosing thoracoabdominal injuries in patients with blunt trauma. Cochrane Injuries Group, editor Cochrane Database Syst Rev2018. https://doi.org/10.1002/14651858.CD012669.pub2. [cited 13 Jun 2019].

[67] Osterwalder J., Mathis G., Hoffmann B. New perspectives for modern trauma management - lessons learned from 25 years FAST and 15 years E-FAST.: 24

[68] Yentis SM. Taking the sting out of needles. J R Soc Med 2005;98:139-40. https:// doi.org/10.1258/jrsm.98.4.139.

[69] Filbet M, Larkin P, Chabloz C, Chirac A, Monsarrat L, Ruer M, et al. Barriers to venipuncture-induced pain prevention in cancer patients: a qualitative study. BMC Palliat Care 2017:16. https://doi.org/10.1186/s12904-016-0180-x.

[70] Egan G, Healy D, O'Neill H, Clarke-Moloney M, Grace PA, Walsh SR. Ultrasound guidance for difficult peripheral venous access: systematic review and meta-analysis. Emerg Med J 2013;30:521-6. https://doi.org/10.1136/emermed-2012201652.

[71] Panebianco NL, Fredette JM, Szyld D, Sagalyn EB, Pines JM, Dean AJ. What you see (sonographically) is what you get: vein and patient characteristics associated with successful ultrasound-guided peripheral intravenous placement in patients with difficult access. Acad Emerg Med 2009;16:1298-303. https://doi.org/10.1111/j. 1553-2712.2009.00520x

[72] Costantino TG, Parikh AK, Satz WA, Fojtik JP. Ultrasonography-guided peripheral intravenous access versus traditional approaches in patients with difficult intravenous access. Ann Emerg Med 2005;46:456-61. https://doi.org/10.1016/j annemergmed.2004.12.026.

[73] Stolz LA, Stolz U, Howe C, Farrell IJ, Adhikari S. Ultrasound-guided peripheral venous access: a meta-analysis and systematic review. J Vasc Access 2015;16:321-6. https://doi.org/10.5301/jva.5000346.

[74] Schoenfeld E, Shokoohi H, Boniface K. Ultrasound-guided peripheral intravenous access in the emergency department: patient-centered survey. West J Emerg Med 2011;12:475-7. https://doi.org/10.5811/westjem.2011.3.1920.

[75] Franco-Sadud R, Schnobrich D, Matthews BK, Candotti C, Abdel-Ghani S, Perez MG et al. Recommendations on the use of ultrasound guidance for central and peripheral vascular access in adults: a position statement of the society of hospital medicine. J Hosp Med 2019;14:E1-22. https://doi.org/10.12788/jhm.3287.

[76] Chambers WA. Nerve blocks in palliative care. Br J Anaesth 2008;101:95-100. https://doi.org/10.1093/bja/aen105.

[77] Klepstad P, Kurita GP, Mercadante S, Sjøgren P. Evidence of peripheral nerve blocks for cancer-related pain: a systematic review. Minerva Anestesiol 2015;81:789-93 Available https://www.ncbi.nlm.nih.gov/pubmed/25384692.

[78] Smith AK, Cenzer IS, Knight SJ, Puntillo KA, Widera E, Williams BA, et al. The epidemiology of pain during the last two years of life. Ann Intern Med 2010;153:563-9. https://doi.org/10.1059/0003-4819-153-9-201011020-00005.

[79] Lillie AK, Read S, Mallen C, Croft P, McBeth J. Musculoskeletal pain in older adults at the end-of-life: a systematic search and critical review of the literature with priorities for future research. BMC Palliat Care 2013;12:27. https://doi.org/10. 1186/1472-684X-12-27.

[80] Bahl A, Bagan M, Joseph S, Brackney A. Comparison of ultrasound and plain radiography for the detection of long-bone fractures. J Emerg Trauma Shock 2018;11:115-8. https://doi.org/10.4103/JETS.JETS_82_17.

[81] Turk F, Kurt AB, Saglam S. Evaluation by ultrasound of traumatic rib fractures missed by radiography. Emerg Radiol 2010;17:473-7. https://doi.org/10.1007/ s10140-010-0892-9.

[82] Draghi F, Urciuoli L, Alessandrino F, Corti R, Scudeller L, Grassi R. Joint effusion of the knee: potentialities and limitations of ultrasonography. J Ultrasound 2015;18:361-71. https://doi.org/10.1007/s40477-015-0180-3.

[83] Kalso E., Edwards J.E., Moore A.R., McQuay H.J. Opioids in chronic non-cancer pain: systematic review of efficacy and safety: Pain. 2004;112: 372-80. doi:10. 1016/j.pain.2004.09.019.

[84] Sibbitt W, Kettwich L, Band P, Chavez-Chiang N, DeLea S, Haseler L, et al. Does ultrasound guidance improve the outcomes of arthrocentesis and corticosteroid injection of the knee? Scand J Rheumatol 2012;41:66-72. https://doi.org/10.3109/ 03009742.2011 .599071$.

[85] Chernack B, Knowlton SE, Kohler MJ. The use of ultrasound in palliative care and hospice. Am J Hospice Palliative Med 2016. https://doi.org/10.1177/ 1049909115625960. cited 7 Jul 2017.

[86] The European Union of Medical Specialists. Training requirements for the specialty of internal medicine, European standards of postgraduate medical specialist training. [cited 21 Jan 2020]. Available: https://www.uems.eu/_data/assets/pdf_ file/0017/44450/UEMS-2016.13-European-Training-Requirements-InternalMedicine.pdf.

[87] Canadian Society of Paliative Care Physicians. Palliative POCUS Course. Available: https://education.emlondon.ca/course/view.php?id =9.

[88] Vargas-Bermúdez A, Valverde-Vega A, Vargas-Aguilar K, Espinoza-Sánchez A. Point-of-care ultrasound in the academic training of palliative medicine residents. J Palliat Med 2017;20:699-700. https://doi.org/10.1089/jpm.2017.0055.

[89] SGUM F.A.Point of care sonografie POCUS Lernzielkatalog. [cited 29 Nov 2018]. 
Available: https://www.fmh.ch/files/pdf20/fa_pocus_anhang_2_d.pdf.

[90] Torres-Macho J, Aro T, Bruckner I, Cogliati C, Gilja OH, Gurghean A, et al. Point-ofcare ultrasound in internal medicine: a position paper by the ultrasound working group of the European federation of internal medicine. Eur J Intern Med. 2019:S0953620519304170https://doi.org/10.1016/j.ejim.2019.11.016.

[91] Wang J, Khan S, Wyer P, Vanderwilp J, Reynolds J, Bethancourt B, et al. The role of ultrasound-guided therapeutic paracentesis in an outpatient transitional care program: a case series. Am J Hosp Palliat Care 2018;35:1256-60. https://doi.org/ 10.1177/1049909118755378.

[92] Atkinson PR, Milne J, Diegelmann L, Lamprecht H, Stander M, Lussier D, et al. Does point-of-care ultrasonography improve clinical outcomes in emergency department patients with undifferentiated hypotension? An international randomized controlled trial from the SHoC-ED investigators. Ann Emerg Med 2018;72:478-89. https://doi.org/10.1016/j.annemergmed.2018.04.002. 